\title{
Profound Induction of Hepatic Cholesteryl Ester Transfer Protein Transgene Expression in Apolipoprotein E and Low Density Lipoprotein Receptor Gene Knockout Mice
}

\author{
A Novel Mechanism Signals Changes in Plasma Cholesterol Levels
}

Lori Masucci-Magoulas, ${ }^{*}$ Andrew Plump, ${ }^{\ddagger}$ Xian Cheng Jiang, ${ }^{*}$ Annemarie Walsh, ${ }^{\ddagger}$ Jan L. Breslow, ${ }^{\ddagger}$ and Alan R. Tall*

*Division of Molecular Medicine, Department of Medicine, College of Physicians and Surgeons, Columbia University, New York 10032; and $\ddagger$ Laboratory of Biochemical Genetics, The Rockefeller University, New York 10021

\begin{abstract}
The plasma cholesteryl ester transfer protein (CETP) mediates the transfer of cholesteryl esters from HDL to other lipoproteins and is a key regulated component of reverse cholesterol transport. Dietary hypercholesterolemia results in increased hepatic CETP gene transcription and higher plasma CETP levels. To investigate the mechanisms by which the liver senses hypercholesterolemia, mice containing a natural flanking region CETP transgene (NFR-CETP transgene) were bred with apo $\mathrm{E}$ or LDL receptor gene knockout mice (E0 or LDLr0 mice). Compared to NFRCETP transgenic $(\mathrm{Tg})$ mice with intact apo $\mathrm{E}$ genes, in NFR-CETP Tg/E0 mice there was an eightfold induction of plasma CETP levels and a parallel increase in hepatic CETP mRNA levels. Other sterol-responsive genes (LDL receptor and hydroxymethyl glutaryl $\mathrm{CoA}$ reductase) also showed evidence of altered regulation with decreased abundance of their mRNAs in the E0 background. A similar induction of plasma CETP and hepatic CETP mRNA levels resulted from breeding the NFR-CETP transgene into the LDL receptor gene knockout background. When placed on a high cholesterol diet, there was a further increase in CETP levels in both E0 and LDLr0 backgrounds. In CETP Tg, CETP Tg/E0, and CETP Tg/LDLr0 mice on different diets, plasma CETP and CETP mRNA levels were highly correlated with plasma cholesterol levels. The results indicate that hepatic CETP gene expression is driven by a mechanism which senses changes in plasma cholesterol levels independent of apo E and LDL receptors. Hepatic sterol-sensitive genes have mechanisms to sense hypercholesterolemia that do not require classical receptor-mediated lipoprotein uptake. (J. Clin. Invest. 1996. 97:154-161.) Key words: CETP - transgenic mouse - hypercholesterolemia - hydroxymethyl CoA reductase $\bullet$ LDL receptor
\end{abstract}

Address correspondence to Alan Tall, Division of Molecular Medicine, Department of Medicine, Columbia University, 630 W. 168th Street, New York, NY 10032. Phone: 212-305-4899; FAX: 212-3055052.

Received for publication 25 June 1995 and accepted in revised form 18 September 1995.

J. Clin. Invest.

(C) The American Society for Clinical Investigation, Inc.

0021-9738/96/01/0154/08 \$2.00

Volume 97, Number 1, January 1996, 154-161

\section{Introduction}

The cholesteryl ester transfer protein $(\mathrm{CETP})^{1}$ is a $74,000-M_{\mathrm{r}}$ glycoprotein which mediates the transfer of cholesteryl esters (CE) from HDL to triglyceride-rich lipoproteins (1). In human genetic CETP deficiency, HDL cholesterol and apo A-I levels are markedly increased, indicating that CETP has a major effect on the catabolism of HDL (2). CETP seems to have an important role in reverse cholesterol transport. By transferring CE from HDL to triglyceride-rich lipoproteins, which are subsequently cleared in the liver, CETP promotes the movement of CE from plasma to the liver $(1,3,4)$. CETP may also promote the transfer of cholesterol from peripheral tissues into HDL both by driving the lecithin: cholesterol acyltransferase reaction $(3,5)$ and by acting in conjunction with hepatic lipase to promote the formation of smaller HDL particles, which are optimal mediators of cellular cholesterol efflux (6).

In animals and humans, plasma CETP levels are increased in response to a high fat, high cholesterol diet (7-9). Studies in human CETP transgenic mice indicate that this is due to an increase in CETP mRNA mediated by an increase in CETP gene transcription, particularly in the liver (10). Recent studies suggest that the increase in CETP mRNA depends on DNA elements found within the proximal promoter of the human CETP gene (11). Little is known of the mechanisms by which dietary hypercholesterolemia leads to changes in CETP gene expression. The major routes for uptake of lipoprotein cholesterol into liver cells are thought to involve the LDL receptorrelated protein (LRP) and LDL receptors (12). The principal ligand mediating lipoprotein clearance by LRP is apo E.

To investigate the mechanism of altered CETP gene expression in the liver, we have crossbred human CETP transgenic mice with apo $\mathrm{E}$ and LDL receptor gene knockout mice. Apo E knockout mice have severe hypercholesterolemia on a chow diet $(13,14)$, and LDL receptor knockout mice develop marked hypercholesterolemia on a high cholesterol diet (15, 16). The results indicate a marked increase of plasma CETP levels paralleling increased hepatic CETP gene expression in both apo E and LDL receptor knockout backgrounds, with further increases of CETP gene expression on a high cholesterol diet. The findings suggest that hepatic sterol sensitive genes have mechanisms to sense hypercholesterolemia that do not require uptake of lipoproteins by LDL receptors or LRP.

1. Abbreviations used in this paper: $\mathrm{C}$, cholesterol; $\mathrm{CE}$, cholesteryl ester; CETP, CE transfer protein; FPLC, fast performance liquid chromatography; HMG, hydroxymethyl glutaryl; LDL receptor-related protein; $\mathrm{mT}$, metallothionein; NFR, natural flanking region; Tg, transgenic. 


\section{Methods}

Transgenic mice. Studies have been conducted with natural flanking region (NFR)-CETP transgenic mice (line 5203), which express a human CETP transgene including $3.2 \mathrm{~kb}$ and $2 \mathrm{~kb}$ of the $5^{\prime}$ and the $3^{\prime}$ flanking region, respectively (10), or metallothionein (mT)-CETP transgenic mice, which express the human CETP transgene under the control of the mouse metallothionein-1 promoter (3). CETP transgenic mice were bred into either the apo E knockout $(\mathrm{E} 0)(13,14)$ or LDL receptor knockout (LDLr0) background (15). To generate the study populations $\mathrm{C} 57 \mathrm{Bl} / 6 \times \mathrm{CBA}$ hybrid mice containing the CETP transgene were crossed with $\mathrm{C} 57 \mathrm{Bl} / 6 \times 129$ hybrid mice containing the apo E0 mutation or $\mathrm{C} 57 \mathrm{Bl} / 6 \times 129$ hybrid mice containing the LDLr0 mutation. The resulting $\mathrm{F} 1$ generation, either apo $\mathrm{E}^{+/-}$or LDL receptor ${ }^{+/-}$mice containing the CETP transgene, was subsequently backcrossed with apo E0 or LDLr0 mice. Male and female transgenic mice and their nontransgenic littermates were used in all experiments. The mice were fed a regular chow diet containing $4 \%$ fat and $0.02 \%$ by weight cholesterol (lab rodent chow 5001; Ralston Purina Co., St. Louis, MO), a "Western-type" diet containing 20\% fat and $0.15 \%$ by weight cholesterol (Research Diets, New Brunswick, NJ; $80 \%$ Purina 5001 mixed with $20 \%$ of hydrogenated coconut oil), or a very high cholesterol $15 \%$ fat diet containing $1.25 \%$ by weight cholesterol, and $0.5 \%$ sodium cholate (Teklad Premier Laboratory Diets, Madison WI; formulated by mixing $75 \%$ rodent chow [containing $11 \%$ fat] and $25 \%$ of a $7.5 \%$ cocoa butter mix). The mice had access to food and water ad lib.

Plasma lipid and lipoprotein analysis. Blood was collected from the retroorbital venous plexus under methoxyflurane anesthesia between 11:00 a.m. and 3:00 p.m. Plasma lipoprotein analysis was performed by fast performance liquid chromatography (FPLC) gel filtration using a Superose 6 column (Pharmacia LKB Biotechnology, Uppsala, Sweden) as described previously (4). A $200-\mu l$ aliquot of pooled plasma (from at least five mice) was loaded onto the column and eluted with TSE buffer (50 mM Tris, $0.15 \mathrm{M} \mathrm{NaCl}, 2 \mathrm{mM}$ EDTA, $\mathrm{pH}$ 7.4) at a constant flow rate of $0.35 \mathrm{ml} / \mathrm{min}$. An aliquot of $80 \mu \mathrm{l}$ from each fraction was used for the determination of total and free cholesterol. Total cholesterol and free cholesterol in plasma and column fractions were assayed by enzymatic methods (Wako Bioproducts, Richmond, VA).

RNA analysis. Total RNA was isolated from liver using the guanidinium thiocyanate method (17). The integrity and quality of all RNA samples were determined by electrophoresis on small agarose borate gels. Various amounts of total RNA from mouse liver were analyzed for CETP, LDL receptor, and 3-hydroxy-3-methylglutaryl(HMG)-CoA reductase mRNAs by solution hybridization-ribonuclease protection assay. For the human CETP mRNA, a human CETP cRNA probe was prepared from the human cDNA which included part of exon 16 and $3^{\prime}$ untranslated region (7). For the mouse LDL receptor mRNA, a mouse LDL receptor cRNA probe corresponding to nucleotides $1247-1308$ was prepared (18). For HMG CoA reductase mRNA, a mouse HMG CoA reductase cRNA probe was prepared from the mouse cDNA corresponding to nucleotides $-3-57$ (18). A $\beta$-actin probe was included in the solution hybridization of the CETP assays, and all CETP mRNA values were normalized for recovery of $\beta$-actin. The assays were performed as described previously (7). Briefly, total RNA from mouse liver was dissolved in $30 \mu \mathrm{l} 80 \%$ formamide, $40 \mathrm{mM}$ Pipes, $0.4 \mathrm{M} \mathrm{NaCl}$, and $1 \mathrm{mM}$ EDTA, pH 6.4, containing $1 \times 10^{5} \mathrm{cpm}$ uridine ${ }^{32} \mathrm{P}$-labeled RNA probe. After denaturation at $85^{\circ} \mathrm{C}$ for $5 \mathrm{~min}$, the mix was incubated for $16 \mathrm{~h}$ at $48^{\circ} \mathrm{C}$. The next day samples were incubated for $2 \mathrm{~h}$ at $30^{\circ} \mathrm{C}$ with 350 $\mu l$ of buffer containing $50 \mathrm{mM}$ sodium acetate, $0.1 \mathrm{M} \mathrm{NaCl}, 2 \mathrm{mM}$ EDTA, pH 5.0, and RNase T2 at a final concentration of $60 \mathrm{U} / \mathrm{ml}$. The reaction was extracted with phenol-chloroform and the ${ }^{32} \mathrm{P}-\mathrm{RNA}-$ RNA hybrid precipitated with carrier tRNA and ethanol. The precipitate was analyzed on a $6 \%$ polyacrylamide-urea sequencing gel. The protected fragment was visualized by autoradiography and quantitated by gel scanning using a laser densitometer (Molecular Dynamics Inc., Sunnyvale, CA).
Determination of plasma CETP concentration and activity. The concentration of CETP in plasma was determined by solid-phase competition RIA using the CETP mAb (TP2) (19). The activity of CETP was determined using radiolabeled lipoprotein substrates in diluted plasma as described previously (20).

Measurement of hepatic cholesterol content. Livers were perfused in vivo with sterile saline and total lipids were isolated as described (21). Free and esterified cholesterol were determined by gas chromatography.

Statistical analysis. Differences between groups were tested by Student's $t$ test or one-way ANOVA where appropriate. All analyses were performed with the Statview ${ }^{\mathrm{TM}} \mathrm{SE}+$ software (Abacus Concepts, Inc., Berkeley, CA). Significance levels using the $t$ test are those for two-tailed test. Data are presented as mean \pm SEM.

\section{Results}

To examine the effects of endogenous hypercholesterolemia on CETP gene expression, we crossed human CETP transgenic mice with either apo E knockout (E0) or LDL receptor knockout (LDLr0) mice. The mice were studied on chow or high cholesterol diets. Plasma cholesterol levels are shown in Table I. Plasma cholesterol is significantly decreased in NFRCETP transgenic ( $\mathrm{Tg}$ ) mice compared to control mice on chow due to the reduction in HDL-cholesterol (C) mediated by CETP (10). Plasma total cholesterol levels on the different diets were similar to published reports $(13-15,22)$. Total cholesterol levels increased 1.3- and 1.7-fold after cholesterol feeding in NFR-CETP Tg and control mice, respectively. Plasma cholesterol on a chow diet was elevated ninefold in E0 mice compared to control mice, and a further increase was observed on a high cholesterol diet. NFR-CETP/E0 mice did not have significantly different total cholesterol levels compared to E0 mice on any of the diets. Compared to controls, plasma total cholesterol was increased 2-3-fold in chow-fed LDLr0 mice, 4-fold on the Western-type diet ( $0.15 \%$ cholesterol), 6-fold after receiving the very high cholesterol $(1.25 \%$ cholesterol) diet for $4 \mathrm{mo}$, and 11-fold after $7 \mathrm{mo}$ on this diet. CETP gene expression did not have a significant effect on plasma total cholesterol levels in NFR-CETP/LDLr0 mice compared to LDLr0 mice on any of the diets.

Plasma CETP concentration and CETP $m R N A$ in EO and LDLr0 backgrounds. Breeding the CETP transgene into the E0 background resulted in a marked (7.5-fold) increase in plasma CETP concentration compared to CETP transgenic controls on the chow diet (Fig. $1 A, P<0.0001$ ). Assay of CETP activity in diluted plasma showed an increase proportionate to the change in CETP mass (not shown). When placed on a high cholesterol diet, the NFR-CETP Tg mice showed a threefold increase in plasma CETP levels, while the NFR$\mathrm{CETP} / \mathrm{E} 0$ mice experienced a further increase in plasma CETP levels to 13 times control. The CETP transgene was also bred into the LDL receptor knockout (LDLr0) background in order to consider a possible requirement for LDL receptors in induction of CETP gene expression in response to hypercholesterolemia. On a chow diet there was a 3.3-fold increase in plasma CETP levels in NFR-CETP/LDLr0 compared with NFR-CETP transgenic mice (Fig. $1 A, P<0.0006$ ). When placed on the very high cholesterol diet $(1.25 \%$ cholesterol $)$ the NFR-CETP Tg/LDLr0 mice showed an 11-fold increase in plasma CETP compared to NFR-CETP Tg mice on chow $(P<$ 0.0006). Plasma CETP was not significantly changed in $\mathrm{mT}$ CETP $\mathrm{Tg}$ mice compared to mT-CETP $\mathrm{Tg} / \mathrm{E} 0$ controls, 
$2.0 \pm 0.32$ vs $1.4 \pm 0.12 \mu \mathrm{g} / \mathrm{ml}$, respectively. In these mice CETP transgene expression is driven by the $\mathrm{mT}$ promoter rather than the sterol-sensitive NFR. Thus CETP induction in response to endogenous hyperlipidemia is dependent on the natural $5^{\prime}$ flanking region of the CETP transgene, suggesting a change in CETP mRNA.

Although CETP is expressed in both central and peripheral tissues (10), the increase in CETP mRNA in E0 and LDLr0 mice was found primarily in the liver. Examination of hepatic CETP mRNA revealed a sevenfold increase in chow-fed NFRCETP Tg/E0 mice compared to NFR-CETP Tg controls and an eightfold increase on the high cholesterol diet (Fig. $1 \mathrm{~B}, \mathrm{P}<$ $0.0003)$. Measurement of CETP mRNA in other principal organs where CETP mRNA is expressed (10) showed a twofold increase in spleen (not significant) and no change in small intestine in NFR-CETP/E0 mice compared to control NFRCETP Tg mice on chow (not shown). Hepatic CETP mRNA abundance was induced threefold in NFR-CETP/LDLr0 mice on a chow diet and sixfold on the high fat, high cholesterol diet compared to NFR-CETP Tg controls (Fig. $1 B, P<0.005$ ). The parallel changes in plasma CETP and hepatic CETP mRNA (compare Fig. 1, $A$ and $B$ ) suggest that the marked increase in plasma CETP levels in NFR-CETP Tg/E0 mice largely results from increased CETP transgene expression in the liver, even though the animals lack an important ligand (apo E) for lipoprotein uptake by $\operatorname{LDLr}$ and LRP $(12,23,24)$. In addition, hepatic CETP gene expression can also be induced by hypercholesterolemia in the absence of LDL receptors.

Correlation of total plasma cholesterol with plasma or hepatic CETP $m R N A$. To help explain the mechanism of plasma CETP induction in CETP transgenic mice bred into the endogenous hypercholesterolemic backgrounds, we correlated plasma total cholesterol and CETP levels in the different lines of CETP Tg mice. With increasing plasma total cholesterol levels there is a progressive increase in plasma CETP levels; plasma CETP was highly correlated with ln plasma cholesterol $\left(r^{2}=\right.$ 0.95, $P<0.0003$; Fig. $2 A)$. A similar correlation was observed between ln plasma total cholesterol and hepatic CETP mRNA (Fig. 2 B). This correlation $\left(r^{2}=0.89, P<0.005\right)$ was not quite as strong, since the induction of hepatic CETP mRNA was not proportionate to increases in plasma cholesterol levels in the CETP/E0 mice (Fig. $1 B$ ). There was a high correlation between plasma CETP concentration and hepatic CETP mRNA in the different groups $\left(r^{2}=0.89, P<0.01\right)$.

HMG CoA and LDLr mRNAs in EO and LDLrO backgrounds. HMG CoA reductase and LDL receptor genes are down-regulated by dietary cholesterol $(24,25)$. Therefore it was of interest to see if these genes also showed altered regulation in the E0 background. The mRNAs for these genes were measured in samples derived from the studies shown in Fig. 1. Hepatic HMG CoA reductase mRNA was decreased in NFRCETP/E0 and E0 mice compared to NFR-CETP Tg mice (Fig. $3 A, P \leq 0.001)$. Hepatic LDL receptor mRNA was also decreased in both NFR-CETP/E0 and E0 mice compared to NFR-CETP Tg mice, but the change was only significant for E0 mice (Fig. $3 B, P<0.04$ ). In another set of animals resulting from a different breeding scheme, hepatic LDL receptor mRNA was significantly down-regulated in E0 versus wildtype mice (not shown). Differences in LDLr or HMG CoA reductase mRNA abundance in NFR-CETP/E0 compared with E0 mice were not significant (Fig. 3, $A$ and $B$ ). These results suggest down-regulation of LDL receptor and $\mathrm{HMG}$ CoA reductase genes in the apo E knockout background with no significant additional effect resulting from CETP expression. Thus several different sterol-sensitive genes show evidence of altered regulation in the livers of E0 mice, consistent with an increased sterol regulatory pool in the liver.

Hepatic cholesterol content. Compared to control mice, E0, and NFR-CETP/E0 mice showed small but significant increases in hepatic CE content (Table II). This could result from an increase in acyl CoA: cholesterol acyltransferase activity; also responding to an increase in the putative sterol regulatory pool. Compared to control mice, NFR-CETP Tg mice showed increases in hepatic cholesterol and $\mathrm{CE}$ as reported previously (4), but CETP did not result in increased cholesterol or $\mathrm{CE}$ in the E0 background. Thus, the increased hepatic cholesterol content mediated by CETP expression (4) may require apo E.

Table I. Plasma Lipids in Different Lines of CETP Transgenic Mice on Various Diets

\begin{tabular}{|c|c|c|c|c|c|c|}
\hline \multirow[b]{2}{*}{ Genotype } & \multicolumn{2}{|c|}{ Chow } & \multicolumn{2}{|c|}{$0.15 \%$ chol } & \multicolumn{2}{|c|}{$1.25 \%$ chol } \\
\hline & $\mathrm{TC}$ & FC & $\mathrm{TC}$ & FC & $\mathrm{TC}$ & $\mathrm{FC}$ \\
\hline & \multicolumn{6}{|c|}{$m g / d l$} \\
\hline Control & $97 \pm 4$ & - & $118 \pm 9$ & $38 \pm 3$ & $162 \pm 18$ & $61 \pm 8$ \\
\hline CETP(5203) & $82 \pm 2 *$ & - & $100 \pm 5$ & $33 \pm 2$ & $109 \pm 15$ & $42 \pm 4^{\ddagger}$ \\
\hline mT-CETP & $68 \pm 6$ & - & & & $128 \pm 5$ & - \\
\hline E0 & $426 \pm 148$ & $154 \pm 4$ & - & - & $1659 \pm 193$ & 298 \\
\hline CETP/E0 & $397 \pm 82$ & $153 \pm 7$ & - & - & $1776 \pm 95$ & $320 \pm 21$ \\
\hline mT-CETP-E0 & $485 \pm 84$ & - & - & - & - & - \\
\hline LDLr0 & $237 \pm 11$ & $53 \pm 4$ & $435 \pm 38$ & - & $2322 \pm 155$ & - \\
\hline CETP/LDLr0 & $212 \pm 8$ & $42 \pm 6$ & $348 \pm 50$ & - & $2060 \pm 73$ & - \\
\hline
\end{tabular}

Different lines of CETP (NFR-line 5203 or mT) Tg mice on various diets. Plasma total (TC) and free cholesterol (FC) were determined by enzymatic assay. Mice were on either a chow, $0.15 \%$ cholesterol, or $1.25 \%$ cholesterol, $0.5 \%$ bile salt diet for $2-3$ wk before blood collection, except LDLr0 and

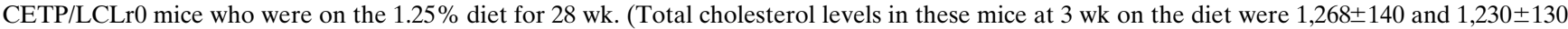
$\mathrm{mg} / \mathrm{dl}$, respectively. Free cholesterol levels were $229 \pm 16$ and $283 \pm 13 \mathrm{mg} / \mathrm{dl}$, respectively). All values are mean \pm SEM from at least six mice per group except CETP on $1.25 \%$ chol, $n=4$. Differences in cholesterol were determined by Student's $t$ test. $* P<0.02 ;{ }^{\ddagger} P<0.05$. 
A

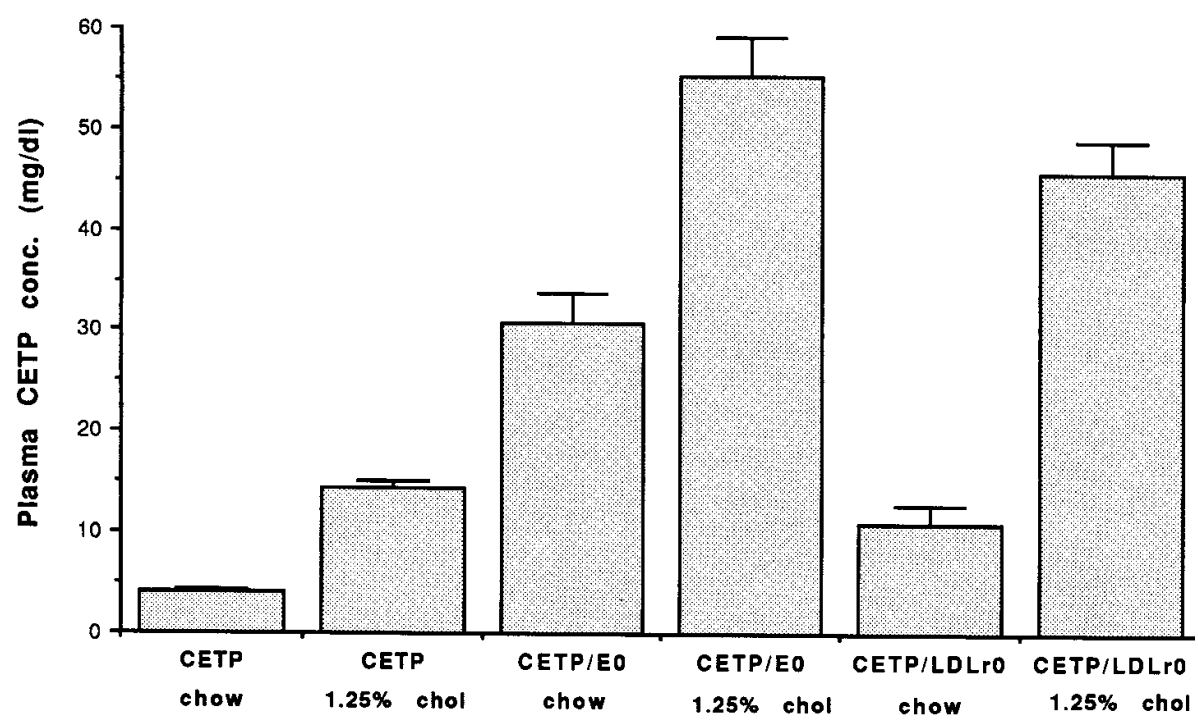

B

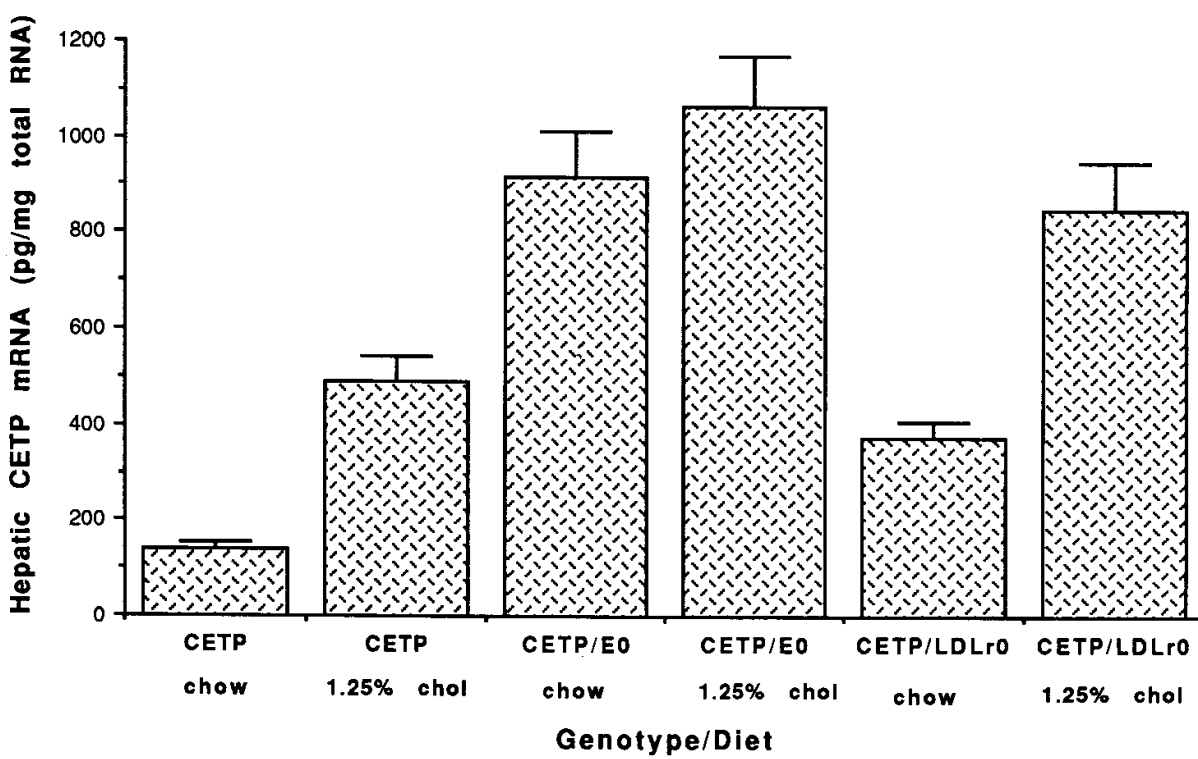

Figure 1. Plasma CETP concentration and hepatic CETP mRNA abundance in NFR-CETP and NFR-CETP/E0 and NFR-CETP/ LDLr0 mice on chow or high fat, high cholesterol $(1.25 \% \mathrm{chol})$ diets. Mice were on either chow or a $1.25 \%$ cholesterol diet for at least 1 wk before they were killed. $(A)$ Plasma CETP was determined by RIA. All values are mean \pm SEM from 5 to 15 mice per genotype/ diet condition. NFR-CETP Tg mice on the $1.25 \%$ cholesterol diet is significantly different to chow $(P \leq 0.0003)$. For the NFR-CETP/ E0 mice both chow and $1.25 \%$ cholesterol diets were significantly different to NFR-CETP Tg mice on the same diet $(P<$ $0.0001)$. The value for NFRCETP/E0 mice on $1.25 \%$ cholesterol diet was significantly different compared to the same genotype on chow diet $(P<0.03)$. The value for the NFR-CETP/LDLr0 mice on either chow or $1.25 \%$ cholesterol diet was significantly different to NFR-CETP Tg mice $(P<$ 0.0006). NFR-CETP/LDLr0 on $1.25 \%$ cholesterol diet was significantly different compared to the same genotype on chow diet $(P<$ 0.0002). (B) Hepatic CETP mRNA abundance in NFR-CETP, NFR-CETP/E0, and NFR-CETP/ LDLr0. Hepatic CETP mRNA abundance was determined by RNAse protection assay. The human CETP riboprobe was hybridized with 15 or $50 \mu \mathrm{g}$ of liver total RNA. The values are mean \pm SEM from 5 to 15 mice per genotype/ diet condition, except for CETP/ LDLr0 mice on chow, $n=3$. NFRCETP Tg on $1.25 \%$ cholesterol diet was significantly different compared to chow diet $(P<$ 0.0004). NFR-CETP/E0 mRNA abundance on either chow or

$1.25 \%$ cholesterol diet was significantly different to NFR-CETP Tg mice on the same $\operatorname{diet}(P<0.0003)$. NFR-CETP/LDLr0 mRNA abundance on either chow or $1.25 \%$ cholesterol diet was significantly different to NFR-CETP Tg mice on the same diet $(P<0.005)$. conc., concentration.

Plasma lipoprotein analysis. The distribution of cholesterol in lipoproteins, as determined by FPLC analysis of pooled plasma is shown in Figs. 4 and 5. In the chow-fed NFR-CETP/ E0 mice there was an $\sim 40 \%$ reduction in HDL-C and a $23 \%$ increase in VLDL-C compared to E0 mice (Fig. 4). In chowfed NFR-CETP/LDLr0 mice there was a $24 \%$ decrease in HDL-C and no change in LDL-C compared to LDLr0 mice (Fig. 5 A). When placed on the Western-type diet $(0.15 \%$ cholesterol), there was only a slight decrease in HDL-C (13\%) in NFR-CETP/LDLr0 mice (Fig. $5 \mathrm{~B}$ ), despite a 2.6-fold induction of plasma CETP by the diet (Fig. 1). On the $1.25 \%$ cholesterol diet there was a marked increase in LDL-C and no detectable change in HDL cholesterol, comparing LDLr0 and
NFR-CETP/LDLr0 Tg mice. Thus, in the LDLr0 background, the dietary induction of plasma CETP became dissociated from the usual effects of CETP on the plasma lipoprotein profile.

\section{Discussion}

By crossing a human CETP transgene with intact flanking sequences into apo $\mathrm{E}$ or LDL receptor gene knockout backgrounds, we have shown that genetically determined hypercholesterolemia can profoundly induce CETP gene expression. There is a marked increase in plasma CETP levels primarily resulting from an increase in hepatic CETP mRNA, even though apo E0 mice show only slight changes in liver choles- 
A

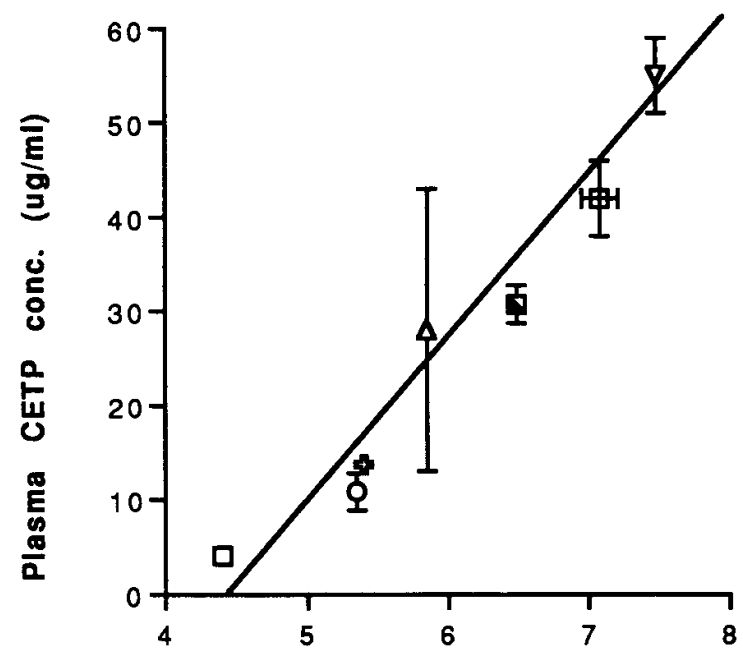

Plasma total cholesterol (natural log)

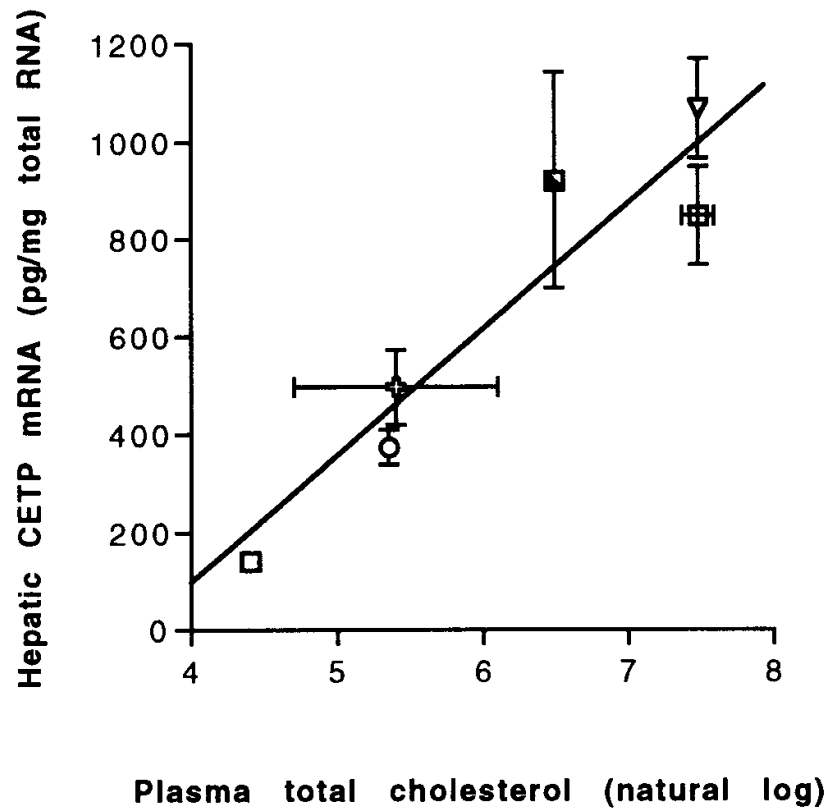

Figure 2. Mean plasma CETP concentration or hepatic CETP mRNA correlated with plasma total cholesterol (expressed as natural log) in NFR-CETP, NFR-CETP/E0, and NFR-CETP/LDLr0 mice on different diets. The same animals were used for both plasma CETP and hepatic CETP mRNA measurement. ( $A$ ) Plasma CETP concentration correlated with plasma total cholesterol $\left(r^{2}=0.95, P<0.0003\right)$. Plasma CETP concentration was determined by RIA. Plasma total cholesterol was determined by enzymatic assay from the same mice. $(B)$ Hepatic CETP mRNA abundance correlated with plasma total cholesterol $\left(r^{2}=0.89, P<0.005\right)$. Hepatic CETP mRNA abundance was quantitated by RNAse protection assay. All values are mean \pm SEM. Each data point represents a different genotype and/or diet. CETP Tg (line 5203) mice on chow (open square, $n=16$ ), CETP Tg on $1.25 \%$ cholesterol (open cross, $n=16$ ), CETP Tg/LDLr0 on chow (open circle, $n=7$ ), CETP Tg/LDLr0 on $0.15 \%$ cholesterol (open triangle, $n=6 ; A$ only), CETP/LDLr0 on $1.25 \%$ cholesterol (hatched square, $n=9$; on diet $1-2$ mo $[A]$; on diet 4 mo $[B]$ ), CETP Tg/E0 on chow (half-filled square, $n=6$ ), and CETP Tg/E0 on $1.25 \%$ (inverted open triangle, $n=5$ ). The curve represents line of best fit for $A$ and $B$.

terol content. There is evidence that other hepatic sterol-sensitive genes also display altered regulation in apo E gene knockout mice. The results suggest that liver cells have a sensitive mechanism to detect plasma cholesterol levels that does not require classical receptor-mediated endocytosis involving apo E or LDL receptors.

The increase in hepatic CETP mRNA abundance with increasing cholesterol levels suggests that liver cells have a sensitive mechanism to detect altered plasma cholesterol levels. This process may also lead to the regulation of other sterolresponsive genes since hepatic LDL receptor and $\mathrm{HMG} \mathrm{CoA}$ reductase mRNAs were decreased in the apo E0 mice. Also, hepatic acyl-CoA: cholesterol $o$-acyltransferase activity seems to be stimulated in response to changes in a hepatic regulatory cholesterol pool, resulting in small increases in CE content in apo E0 mice (Table II). The sterol-sensing mechanism is unlikely to involve receptor-mediated endocytosis by LDL receptors or LRP, since it operates efficiently in both apo E0 and LDLr0 mice. Conceivably, in apo E0 mice the mechanism could involve uptake of apo B lipoproteins by LDL receptors. However, in compound LDLr0/apo E0 mice, plasma cholesterol levels are the same as in apo E0 mice, indicating that this pathway plays a minor role in clearing plasma cholesterol in E0 mice (26). Furthermore, since LDL receptors are efficiently down-regulated as they internalize lipoprotein cholesterol
(12), it appears improbable that this pathway would be involved in a feedback loop that involves a positive response (i.e., increased CETP gene transcription) in response to hypercholesterolemia. Thus, we conclude that the sensing mechanism does not require classical receptor-mediated endocytosis. One possibility is that lipoprotein free cholesterol, markedly increased in apo E knockout mice (Table I), equilibrates with plasma membrane and intracellular pools of free cholesterol (presumably in the endoplasmic reticulum) which then alter the expression of sterol-sensitive genes. Another possibility is that lipoprotein cholesterol is taken up by nonspecific endocytosis or by an unknown hepatic receptor, leading to changes in regulatory sterol pools.

Recently, there has been tremendous progress in the understanding of the mechanism of regulation of sterol-sensitive genes. The LDL receptor gene has been shown to be regulated by transcription factors (SREBPs) which reside in the endoplasmic reticulum and are activated by proteolysis when cells are deprived of cholesterol $(27,28)$. The CETP gene is up-regulated by sterols, and the proximal promoter of the CETP gene does not contain the consensus sterol regulatory element of the LDL receptor gene. Thus, the mechanism of altered transcription of the CETP gene is likely to be distinctive. However, the proximal mechanisms for sensing changes in plasma cholesterol, possibly involving minute changes in endoplasmic 
A

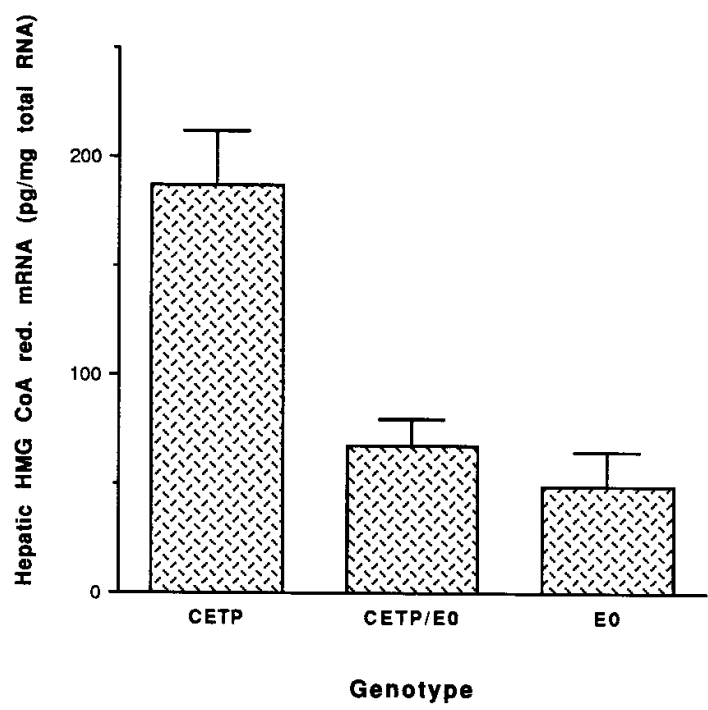

B

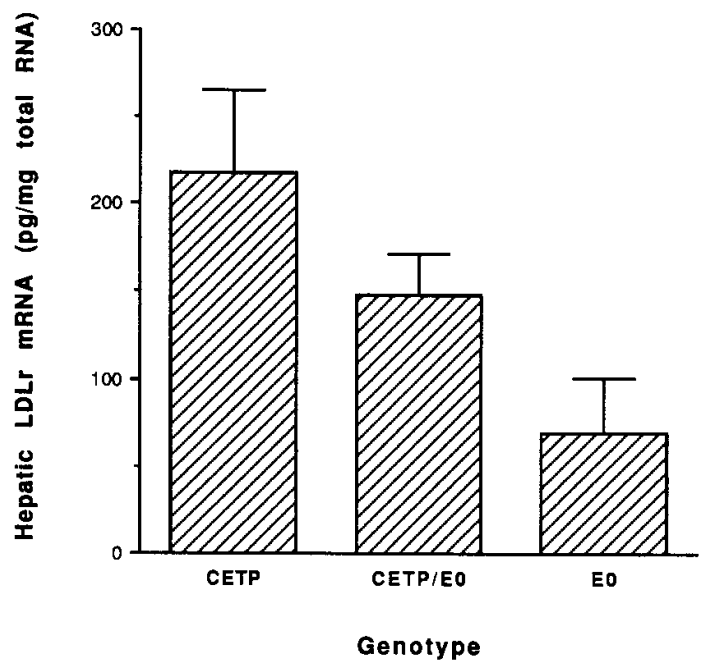

Figure 3. Hepatic HMG CoA reductase and LDL receptor mRNA abundance in NFR-CETP, NFR-CETP/E0, and E0, chow-fed mice. All values are mean \pm SEM for five to nine mice per genotype. $(A)$ Hepatic HMG CoA reductase (red.) mRNA abundance was determined by RNAse protection assay. The mouse HMG CoA reductase riboprobe was hybridized with $50 \mu \mathrm{g}$ total RNA. Values for NFRCETP/E0 and E0 mice were significantly different to NFR-CETP Tg mice $(P \leq 0.001)$. $(B)$ Hepatic LDL receptor mRNA abundance in NFR-CETP, NFR-CETP/E0, and E0 chow-fed mice. LDL receptor mRNA abundance was determined by RNAse protection assay. The mouse LDL receptor riboprobe was hybridized with $50 \mu \mathrm{g}$ total RNA. The value for E0 mice was significantly different to NFRCETP Tg mice $(P \leq 0.04)$.

reticulum cholesterol content levels, may be shared by CETP, HMG CoA reductase, LDLr, and other sterol-sensitive genes.

A general relationship between plasma cholesterol levels and CETP levels was suspected by Zilversmit and Son (29), who showed that cholesterol-fed rabbits or Watanabe rabbits with defective LDL receptors had two- to threefold increases in plasma CETP activity. However, Quig and Zilversmit (30) thought that such a relationship would likely reflect a passive
Table II. Hepatic Cholesterol Content in Different Lines of Transgenic Mice

\begin{tabular}{|c|c|c|}
\hline Genotype & $\mathrm{FC}$ & $\mathrm{CE}$ \\
\hline & \multicolumn{2}{|c|}{$\mu g / m g$ wet hepatic tissue } \\
\hline Control & $2.15 \pm 0.11 *$ & $0.03 \pm 0.03 *$ \\
\hline E0 & $2.25 \pm 0.06^{*}$ & $0.63 \pm 0.15^{\ddagger}$ \\
\hline NFR-CETP/E0 & $1.93 \pm 0.09^{\S}$ & $0.43 \pm 0.07^{\ddagger}$ \\
\hline NFR-CETP & $2.50 \pm 0.09^{\ddagger}$ & $0.50 \pm 0.06^{\ddagger}$ \\
\hline
\end{tabular}

Livers were perfused in vivo and hepatic lipids were subsequently isolated as described (21). Free cholesterol (FC) and CE were determined by gas liquid chromatography. Mice were on a chow diet. Values are mean \pm SEM from three to four mice per group and assayed at the same time. Differences in cholesterol were determined by one way ANOVA. Means with different superscripts represent significantly different values, $P<0.05$.

increase in plasma CETP levels due to increased binding to cholesterol-rich lipoproteins. The increase in plasma CETP levels, whether of dietary or endogenous origin, is mediated by increased CETP gene expression. This is shown by lack of change of plasma CETP in mice containing a metallothionein promoter-driven CETP transgene in the apo E knockout background and a close correlation between plasma CETP concentration and hepatic CETP mRNA in the different groups. However, in E0 and LDLr0 backgrounds on the very high cholesterol diet, the increase in plasma CETP concentration seemed disproportionately larger than the increase in hepatic CETP mRNA (Fig. 1, $A$ and $B$ ), suggesting additional mechanisms such as impaired clearance of plasma CETP at very high plasma cholesterol concentrations.

Why is there such marked sensitivity of CETP gene expression to increases in plasma cholesterol levels? The answer to

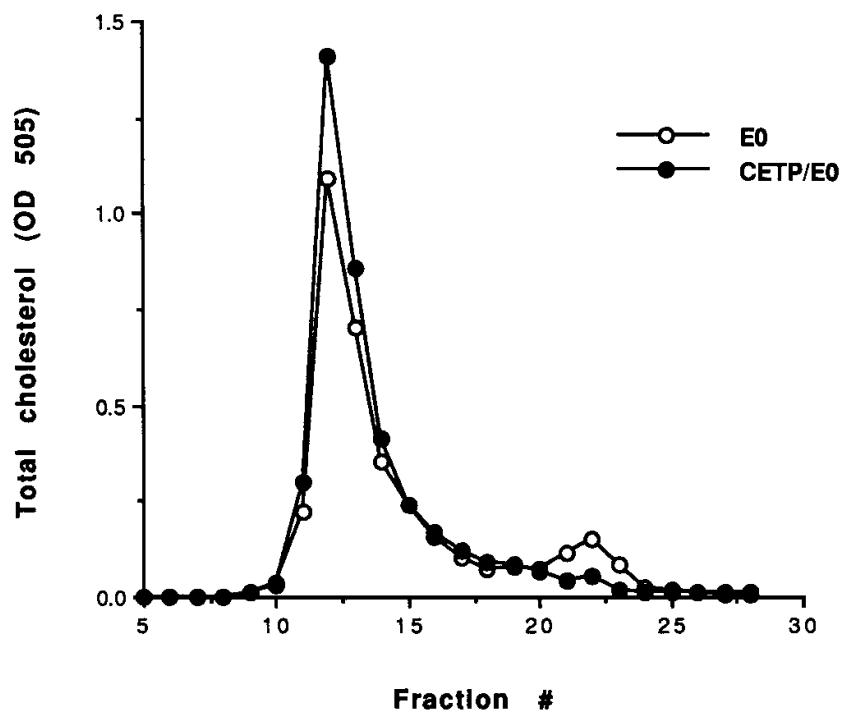

Figure 4. Total plasma cholesterol concentration in plasma lipoproteins in NFR-CETP/E0 and E0 mice. FPLC was performed with 200 $\mu \mathrm{l}$ of pooled plasma from at least six mice per group. Total cholesterol was determined by enzymatic assay from an $80-\mu l$ aliquot of each fraction. NFR-CETP/E0 (closed circles) and E0 mice (open circles) were on a chow diet. 
A

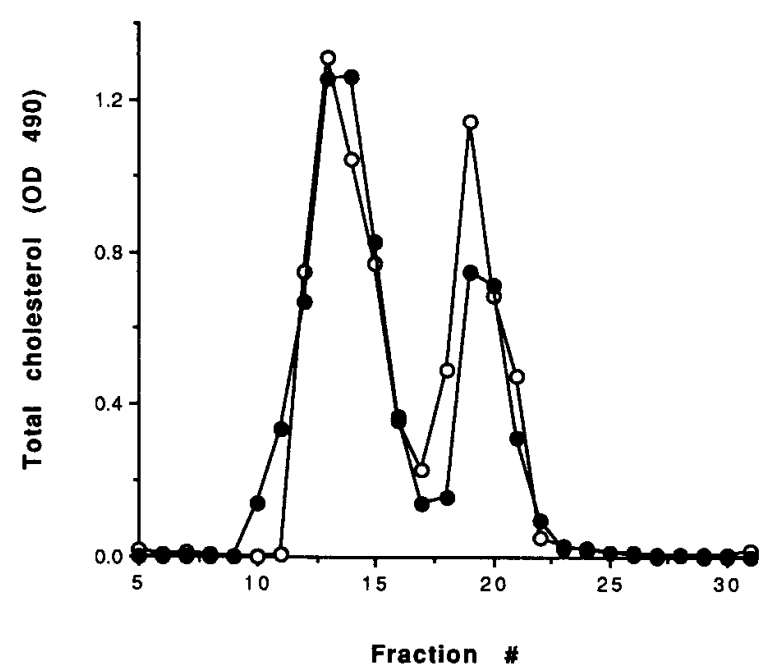

B

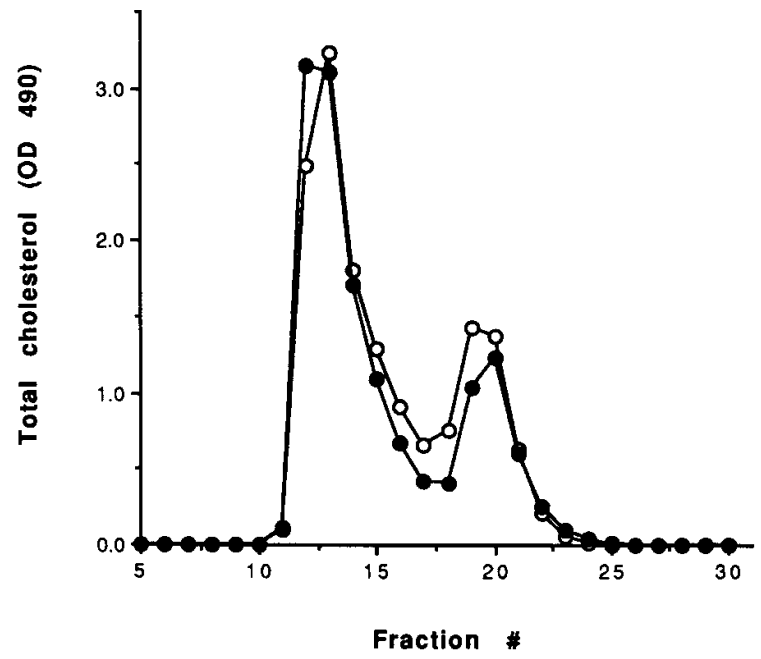

Figure 5. Total plasma cholesterol concentration in plasma lipoproteins of NFR-CETP/LDLr0 and LDLr0 mice. FPLC was performed with $200 \mu$ l of pooled plasma from 5 to 13 mice per group. Total cholesterol was determined by enzymatic assay from an $80-\mu l$ aliquot of each fraction. $(A)$ Total cholesterol in plasma lipoproteins of NFRCETP/LDLr0 (closed circles) and LDLr0 (open circles) on a chow diet. (B) Total cholesterol in plasma lipoproteins of NFR-CETP/ LDLr0 (closed circles) and LDLr0 (open circles) on a Western-type $(0.15 \%$ cholesterol $)$ diet.

this question may lie in an understanding of the function of CETP in cholesterol homeostasis. By stimulating the transfer of cholesteryl esters from HDL to triglyceride-rich lipoproteins, CETP normally enhances the return of cholesterol from the plasma to the liver, resulting in a lowering of plasma cholesterol levels $(1,3,4)$. In chow-fed CETP transgenic mice, there is a decrease in plasma total cholesterol and HDL cholesterol, compared to control mice $(3,4)$; these effects of CETP expression are exaggerated in hypertriglyceridemic apo CIII transgenic mice (31). In CETP transgenic mice there is a marked depletion of lipoprotein free cholesterol (expressed as $\mathrm{C} / \mathrm{CE}$ or $\mathrm{C} / \mathrm{PPL}$ ratios) in all lipoprotein classes, suggesting that CETP may stimulate cholesterol esterification in vivo, possibly by transferring $\mathrm{CE}$ out of HDL and thereby driving the lecithin:cholesterol acyltransferase reaction $(3,5)$. If the hepatic sensor of hypercholesterolemia which drives CETP expression is, in fact, monitoring plasma free cholesterol concentration, there may be a negative feedback loop where increased plasma free cholesterol concentration drives CETP gene expression, leading to decreased plasma free cholesterol. However, the profound increase in plasma CETP in E0 and LDLr0 mice was not accompanied by proportionate effects of CETP on total plasma cholesterol, free cholesterol, or HDL-C. These normal functions of CETP may be impaired, since E0 and LDLr0 mice do not have hypertriglyceridemia (13-15), which normally drives the cholesteryl ester transfer process $(31,32)$.

In cross-sectional human studies, plasma CETP levels have generally been found to correlate with plasma cholesterol levels $(5,20)$. For example, in a recent study, compared with 50 normolipidemic males, 113 hypercholesterolemic individuals had a $42 \%$ higher mean CETP activity (proportional to mass), and $\sim 60 \%$ of these patients had CETP activities outside the normal range. A comparable elevation of CETP was observed in 47 patients with combined hyperlipidemia. Although these studies were interpreted to suggest that increased plasma CETP levels might contribute to hypercholesterolemia (33), the present results show a marked sensitivity of human CETP gene expression to hypercholesterolemia. Moreover, the marked induction of CETP in apo E0 and LDLr0 mice was not accompanied by corresponding large increases in VLDL or LDL cholesterol. Thus, the correlation between plasma CETP levels and plasma cholesterol levels in humans probably largely reflects increased CETP gene expression, secondary to hypercholesterolemia.

It has long been known that sterol-sensitive genes could be regulated by direct delivery of nonlipoprotein cholesterol in cultured cells $(34,35)$, and also that nonreceptor pathways play a role in the clearance of LDL from plasma (36). The present study provides in vivo evidence that nonreceptor pathways for delivering cholesterol to liver cells may be important in the physiological regulation of sterol-sensitive genes.

\section{Acknowledgments}

This work was supported by National Institutes of Health grants HL54591 and 43165.

\section{References}

1. Tall, A. R. 1986. Plasma lipid transfer proteins. J. Lipid Res. 27:359-365. 2. Inazu, A., M. Brown, C. Hesler, L. B. Agellon, J. Koizumi, K. Takata, Y. Maruhama, H. Mabuchi, and A. R. Tall. 1990. Increased high-density lipoprotein levels caused by a common cholesteryl-ester transfer protein gene mutation. N. Engl. J. Med. 323:1234-1238.

3. Agellon, L. B., A. Walsh, T. Hayek, P. Moulin, X. C. Jiang, S. Shelanski, J. Breslow, and A. R. Tall. 1991. Reduced high density lipoprotein cholesterol in human cholesteryl ester transfer protein transgenic mice. J. Biol. Chem. 266: 10796-10801.

4. Jiang, X. C., L. Masucci-Magoulas, J. Mar, M. Lin, A. Walsh, J. Breslow, and A. Tall. 1993. Down-regulation of mRNA for the low density lipoprotein receptor in transgenic mice containing the gene for human cholesteryl ester transfer protein. J. Biol. Chem. 268:27406-27412.

5. Chajek, T., L. Aron, and C. J. Fielding. 1980. Interaction of lecithin:cholesterol acyltransferase and cholesteryl ester transfer protein in the transport of cholesteryl ester into sphingomyelin liposomes. Biochemistry. 19:3673-3677.

6. Fielding, C. J., and P. E. Fielding. 1995. Molecular physiology of reverse cholesterol transport. J. Lipid Res. 36:211-228. 
7. Quinet, E. M., L. B. Agellon, P. A. Kroon, Y. L. Marcel, Y. C. Lee, M. E. Whitlock, and A. R. Tall. 1990. Atherogenic diet increases cholesteryl ester transfer protein (CETP) mRNA levels in rabbit liver. J. Clin. Invest. 85:357363.

8. Quinet, E., A. R. Tall, R. Ramakrishnan, and L. Rudel. 1991. Plasma lipid transfer protein as a determinant of the atherogenicity of monkey plasma lipoproteins. J. Clin. Invest. 87:1559-1566.

9. Martin, L. J., P. W. Connelly, D. Nancoo, N. Wood, Z. J. Zhang, G. Maguire, E. Quinet, A. R. Tall, Y. L. Marcel, and R. McPherson. 1993. Cholesteryl ester transfer protein and high density lipoprotein responses to cholesterol feeding in men: relationship to apolipoprotein E genotype. J. Lipid Res. 34:437446.

10. Jiang, X. C., L. B. Agellon, A. Walsh, J. Breslow, and A. R. Tall. 1992. Dietary cholesterol increases transcription of the human cholesteryl ester transfer protein in transgenic mice: dependence on the natural flanking sequences. $J$. Biol. Chem. 90:1290-1295.

11. Oliveira, H., L. Agellon, R. Chouinard, A. Verhoeven, X. Jiang, A. Walsh, J. L. Breslow, and A. R. Tall. 1994. Human CETP gene proximal promoter contains dietary cholesterol responsive elements and mediates expression in small intestine and periphery but not liver. Circulation. 90:I-401.

12. Willnow, T. E., Z. Sheng, S. Ishibashi, and J. Herz. 1994. Inhibition of hepatic chylomicron remnant uptake by gene transfer of a receptor antagonist. Science (Wash. DC). 264:1471-1474.

13. Plump, A. S., J. D. Smith, T. Hayek, K. Aalto-Setala, A. Walsh, J. Verstuyft, E. Rubin, and J. Breslow. 1992. Severe hypercholesterolemia and atherosclerosis in apolipoprotein E-deficient mice created by homologous recombination in ES cells. Cell. 71:343-353.

14. Zhang, S. H., R. L. Reddick, J. Piedrahita, and N. Maeda. 1992. Spontaneous hypercholesterolemia and arterial lesions in mice lacking apolipoprotein E. Science (Wash. DC). 258:468-471.

15. Ishibashi, S., M. Brown, J. Goldstein, R. D. Gerard, R. E. Hammer, and J. Herz. 1993. Hypercholesterolemia in low density lipoprotein receptor knockout mice and its reversal by adenovirus-mediated gene delivery. J. Clin. Invest. 92:883-893.

16. Ishibashi, S., J. L. Goldstein, M. S. Brown, J. Herz, and D. K. Burns. 1994. Massive xanthomatosis and atherosclerosis in cholesterol-fed LDL receptor-negative mice. J. Clin. Invest. 93:1885-1893.

17. Chomczynski, P., and N. Sacchi. 1987. Single-step method of RNA isolation by acid guanidinium thiocyanate-phenol-chloroform extraction. Anal. Chem. 162:156-159.

18. Rudling, M. 1992. Hepatic mRNA levels for the LDL receptor and HMG CoA reductase show coordinate regulation in vivo. J. Lipid Res. 33:493501.

19. Tall, A. R., E. Granot, R. Brocia, I. Tabas, C. Hesler, K. Williams, and M. Denke. 1987. Accelerated transfer of cholesteryl esters in dyslipidemic plasma: role of cholesteryl ester transfer protein. J. Clin. Invest. 79:1217-1225.

20. Marcel, Y. L., R. McPherson, M. Hogue, H. Czarnecka, Z. Zawadzki, P. Weech, M. Whitlock, A. R. Tall, and R. W. Milne. 1990. Distribution and concentration of cholesteryl ester transfer protein in plasma of normolipidemic subjects. J. Clin. Invest. 85:10-17.

21. Carr, T. P., C. J. Andersen, and L. L. Rudel. 1993. Enzymatic determi- nation of triglyceride, free cholesterol, and total cholesterol in tissue lipid extracts. Clin. Biochem. 26:39-42.

22. Zhang, S., R. Reddick, B. Burkey, and N. Maeda. 1994. Diet-induced atherosclerosis in mice heterozygous and homozygous for apolipoprotein E gene disruption. J. Clin. Invest. 94:937-945.

23. Biesiegel, U., W. Weber, G. Ihrke, J. Herz, and K. K. Stanley. 1989. The LDL-receptor-related protein, LRP, is an apolipoprotein E-binding protein. Nature (Lond.). 341:162-164.

24. Dawson, P. A., S. L. Hofmann, D. R. Westhuyzen, T. C. Budhoff, M. S. Brown, and J. L. Goldstein. 1988. Sterol-dependent repression of LDL receptor promoter mediated by 16-base pair sequence adjacent to binding site for transcription factor SP-1. J. Biol. Chem. 263:3372-3379.

25. Goldstein, J. L., and M. S. Brown. 1990. Regulation of the mevalonate pathway. Nature (Lond.). 343:425-430.

26. Ishibashi, S., J. Herz, N. Maeda, J. Goldstein, and M. Brown. 1994. The two-receptor model of lipoprotein clearance: tests of the hypothesis in "knockout" mice lacking the low density lipoprotein receptor, apolipoprotein E, or both proteins. Proc. Natl. Acad. Sci. USA. 91:4431-4435.

27. Wang, X., R. Sato, M. Brown, X. Hua, and J. Goldstein. 1994. SREBP-1, a membrane-bound transcription factor released by sterol-regulated proteolysis. Cell. 77:53-62.

28. Sheng, Z., H. Otani, M. S. Brown, and J. L. Goldstein. 1995. Independent regulation of sterol regulatory element binding proteins 1 and 2 in hamster liver. Proc. Natl. Acad. Sci. USA. 92:935-938.

29. Son, Y.-S., and D. B. Zilversmit. 1986. Increased lipid transfer activities in hyperlipidemic rabbit plasma. Arteriosclerosis. 6:345-351.

30. Quig, D. W., and D. B. Zilversmit. 1990. Plasma lipid transfer activities. Annu. Rev. Nutr. 10:169-193.

31. Hayek, T., N. Azrolan, R. B. Verdery, A. Walsh, T. Chajek-Shaul, L. B. Agellon, A. R. Tall, and J. Breslow. 1993. Hypertriglyceridemia and cholesteryl ester transfer protein interact to dramatically alter high density lipoprotein levels, particle sizes, and metabolism: studies in transgenic mice. J. Clin. Invest. 92: 1143-1152.

32. Mann, C. J., F. T. Yen, A. M. Grant, and B. E. Bihain. 1991. Mechanism of plasma cholesteryl ester transfer in hypertriglyceridemia. J. Clin. Invest. 88: 2059-2066.

33. Tato, F., L. Vega, A. Tall, and S. Grundy. 1995. Relationship between cholesterol ester transfer protein activities and lipoprotein cholesterol in patients with hypercholesterolemia and combined hyperlipidemia. Arterioscler Thromb. and Vasc. Biol. 15:112-120.

34. Goldstein, J. L., and M. S. Brown. 1976. The LDL pathway in human fibroblasts: a receptor-mediated mechanism for the regulation of cholesterol metabolism. Curr. Topics Cell. Regul. 11:147-181.

35. Brown, M. S., and J. L. Goldstein. 1976. Analysis of a mutant strain of human fibroblasts with a defect in the internalization of receptor-bound low density lipoprotein. Cell. 9:663-674.

36. Attie, A. D., R. C. Pittman, and D. Steinberg. 1980. Metabolism of native and lactosylated human low density lipoprotein: evidence for two pathways for catabolism of exogenous proteins in rat hepatocytes. Proc. Natl. Acad. Sci. USA. 77:5923-5927. 